\begin{tabular}{|c|l|}
\hline Title & $\begin{array}{l}\text { Gene cloning of cold-adapted isocitrate ly ase from a psychrophilic bacterium, Colwellia psychrerythraea, and analysis } \\
\text { of amino acid residues involved in cold adaptation of this enzyme }\end{array}$ \\
\hline Author(s) & Sato, Y uhya; W atanabe, Seiya; Y amaoka, Naoto; Takada, Y asuhiro \\
\hline Citation & $\begin{array}{l}\text { Extremophiles, 12(1), 107-117 } \\
\text { https://doi.org/10.1007/300792-007-0115-9 }\end{array}$ \\
\hline Issue Date & 2008-01 \\
\hline Doc URL & http://hdl.handle.net/2115/32824 \\
\hline Rights & The original publication is avail lable at www.springerlink.com \\
\hline Type & article (author version) \\
\hline File Information & CpICL2.pdf \\
\hline
\end{tabular}

Instructions for use 


\section{Gene cloning of cold-adapted isocitrate lyase from a psychrophilic bacterium, Colwellia psychrerythraea, and analysis of amino acid residues involved in cold adaptation of this enzyme}

Yuhya Sato • Seiya Watanabe • Naoto Yamaoka • Yasuhiro Takada

15 Y. Sato $\cdot$ S. Watanabe $\cdot$ N. Yamaoka $\cdot$ Y. Takada $(\square)$

Division of Biological Sciences, Graduate School of Science, Hokkaido

University, Kita 10-jo Nishi 8-chome, Kita-ku, Sapporo 060-0810, Japan

E-mail: ytaka@sci.hokudai.ac.jp

Tel.: +81-11-706-2742

20 Fax: +81-11-706-2742

S. Watanabe

Institute of Advanced Energy, Kyoto University, Uji, Kyoto 611-0011, Japan

$25 \quad$ N. Yamaoka

Laboratory of Plant Pathology, Faculty of Agriculture, Ehime University, Matsuyama 790-8566, Japan 
Abstract The gene (icl) encoding cold-adapted isocitrate lyase (ICL) of a psychrophilic bacterium, Colwellia psychrerythraea, was cloned and sequenced. Open reading frame of the gene was $1,587 \mathrm{bp}$ in length and corresponded to a polypeptide composed of 528 amino acids. The deduced amino acid sequence

5 showed high homology with that of cold-adapted ICL from other psychrophilic bacterium, Colwellia maris ( $88 \%$ identity), but the sequential homology with that of the Escherichia coli ICL was low (28\% identity). Primer extension analysis revealed that transcriptional start site for the C. psychrerythraea icl gene was guanine, located at 87 bases upstream of translational initiation codon.

10 The expression of this gene in the cells of an E. coli mutant defective in ICL was induced by not only low temperature but also acetate. However, cis-acting elements for cold-inducible expression known in the several other bacterial genes were absent in the promoter region of the C. psychrerythraea icl gene. The substitution of Ala214 for Ser in the C. psychrerythraea ICL introduced by point mutation resulted in the increased thermostability and lowering of the specific activity at low temperature, indicating that Ala214 is important for psychrophilic properties of this enzyme.

Key words Psychrophlic bacterium • Colwellia psychrerythraea Isocitrate lyase $\bullet$ Cold-adapted enzyme $\bullet$ Cold-inducible gene expression 


\section{Introduction}

Temperature, especially low temperature, has important effects on growth of living organisms and defines their growth limits because the catalytic activities

5 of enzymes in the cells are strongly dependent on temperature. Nevertheless, microorganisms called as psychrophilic bacteria can survive and live even in permanently cold environment on Earth. The cold-adapted enzymes, which exhibit higher catalytic activity at low temperature and lower thermostability than the counterparts from mesophilic and thermophilic bacteria, are one of critical mechanisms for environmental adaptation of these bacteria because such enzymes can compensate the decrease of catalytic function at low temperature. It has been reported that these common properties of cold-adapted enzymes are attributable to their pronounced structural flexibility, which makes them possible to accomplish easy binding of the substrates to their active sites at low temperature and rapid conformational changes for the catalysis without large energetic loss (Gerday et al. 1997; Fields and Somero 1998; Geolette et al. 2003; Cavicchioli et al. 2002).

Isocitrate lyase (ICL, EC 4.1.3.1) catalyses the cleavage of isocitrate to glyoxylate and succinate, the first step in the glyoxylate cycle designated by Kornberg and Krebs (1957). Then, the second enzyme of this cycle, malate synthase, serves the conversion of glyoxylate and acetyl-CoA to malate. Thus, the glyoxylate cycle can bypass several reactions for the formation of succinate and malate from isocitrate in the TCA cycle and is known to be important for the metabolism of acetate and fatty acids in plants and microorganisms (Kornberg 1966; Vanni et al. 1990; Cozzone 1998). Furthermore, ICL is known to be highly induced when microorganisms are grown on acetate (Vanni et al. 1990).

It has been reported that ICL (CpICL) of a psychrophillic bacteria, Colwellia 
psychrerythraea (D’Aoust and Kushner 1972; Deming et al. 1988), exhibits several features as a cold-adapted enzyme, as well as the corresponding enzyme (CmICL) from Colwellia maris (Takada et al. 1979; Yumoto et al. 1998), another psychrophilic bacterial species of the same genus (Watanabe et al. 2001, 2002a, b). Namely, the CpICL showed maximum activity at $25^{\circ} \mathrm{C}$ and completely inactivated even by brief incubation for $2 \mathrm{~min}$ at $30^{\circ} \mathrm{C}$ (Watanabe et al. 2002b). Furthermore, the maximum catalytic efficiency of this enzyme was observed at $20^{\circ} \mathrm{C}$. Preliminary experiments revealed that the expression of gene encoding this enzyme may be induced by low temperature.

In this study, we cloned the gene encoding the cold-adapted CPICL and examined effect of sodium acetate and temperature on the gene expression. In addition, to obtain information on the molecular mechanisms for high catalytic function of the cold-adapted ICL at low temperature, several point mutations were introduced into the icl gene and several properties of the mutated enzymes were examined.

\section{Materials and methods}

Bacteria, plasmids and culture conditions

The psychrophilic Colwellia psychrerythraea NRC 1004 (D'Aoust and Kushner 1972; Deming et al. 1988) was grown at $15^{\circ} \mathrm{C}$ with vigorous shaking in a nutrient medium consisting of $1 \%$ meat extract, $40 \mathrm{mM} \mathrm{MgCl}_{2}, 3 \% \mathrm{NaCl}$ and 25 $\mathrm{mM}$ sodium acetate as a carbon source. E. coli XL1-Blue (Stratagene) and TOP10 (Invitrogen) were used for the propagation of plasmids and the 
production of His-tagged recombinant ICL proteins from expression vectors, respectively. A mutant defective in ICL of E. coli, ACA421 (Watanabe et al. 2002a), and its parent strain, KM22 (a $\triangle \operatorname{recBCD}$ mutant; Kenan 1998), were used in the experiments for icl gene expression. Unless otherwise stated, these

5 E. coli strains were grown at $37^{\circ} \mathrm{C}$ with vigorous shaking in Luria-Bertani (LB) medium (Sambrook and Russell 2001). Plasmids pBluscript KS(+) (pBS; Stratagene) and pTrcHisB (Invitrogen) were used as vectors for cloning the icl gene and conferring $\mathrm{N}$-terminal (His) ${ }_{6}$-tag on the expressed proteins, respectively.

Cloning of the C. psychrerythraea icl gene

Genomic PCR was performed to obtain a nucleotide probe for icl gene encoding the CpICL. Upstream primer, 5'-TCNAAYTAYCARAGYGCNATHGARGC -3', was designed from SNYQSAIEA, the sequence between the first and ninth amino acid residues from the N-terminal of CpICL (Watanabe et al. 2002b). Downstream primer, 5'-CCRTCYTGRTGNCCRCAYTGYTT-3', was designed from KQCGHQDG, the amino acid sequence of the CmICL corresponding to highly conserved regions of the icl genes cloned from various organisms (Watanabe et al. 2002a). Chromosomal DNA of C. psychrerythraea was purified as described previously (Ishii et al. 1993). Amplification was carried out for 30 cycles in a DNA thermal cycler 2400 (Perkin-Elmer) in a $50 \mu 1$ of reaction mixture containing $1.4 \mu \mathrm{g}$ genomic DNA, 10 pmol each upstream and downstream primer and 1 unit KOD-plus DNA polymerase (Toyobo) in a buffer system prepared by the manufacturer. Cycling conditions were as follows: denaturation at $94^{\circ} \mathrm{C}$ for $15 \mathrm{~s}$, annealing at $50^{\circ} \mathrm{C}$ for $30 \mathrm{~s}$ and extension at $68^{\circ} \mathrm{C}$ 
for $1 \mathrm{~min}$, for each of 30 cycles. PCR products with a predicted length of about $700 \mathrm{bp}$ were purified and ligated to the SmaI site of pBS. Nucleotide sequences of the PCR products were determined by using a BigDye terminator Cycle Sequencing FS Ready Reaction kit (Applied Biosystems) with an ABI PRISM Genetic Analyzer 310. Plasmid carrying the 668 bp PCR product with a nucleotide sequence similar to the C. maris icl gene was termed pCP10. This insert DNA was amplified by PCR with pCP10 as template DNA and was used as probe for genomic Southern and colony hybridizations.

Genomic Southern hybridization was carried out as described previously (Watanabe et al. 2002b) with some modifications. The chromosomal DNA of C. psychrerythraea digested with several restriction enzymes was separated by $1 \%$ agarose gel electrophoresis and the DNA fragments on the gel were transferred onto nylon membrane, Hybond- $\mathrm{N}^{+}$(Amersham Pharmacia Biotech). Hybridization was carried out overnight at $60^{\circ} \mathrm{C}$ with the probe labeled with $\left[\alpha-{ }^{32} \mathrm{P}\right] \mathrm{dCTP}$ and a random primer labeling kit (Takara). The blotted membrane was washed successively in $2 \times \mathrm{SSC}(1 \times \mathrm{SSC}$ is composed of $15 \mathrm{mM}$ sodium citrate $\mathrm{pH} 7.0$ and $0.15 \mathrm{M} \mathrm{NaCl}$ ) containing $0.1 \%(\mathrm{w} / \mathrm{v}) \mathrm{SDS}$ for $10 \mathrm{~min}$ at room temperature and then twice with the same solution for $20 \mathrm{~min}$ at $60^{\circ} \mathrm{C}$. About 3 $\mathrm{kbp}$ of SpeI fragments hybridized with the probe were cloned into pBS and the resultant plasmids were transformed into E. coli XL1-Blue. Colony hybridization was then carried out by using the same probe as Southern hybridization. The blotted membranes were washed as described above. A colony with strongest signal was selected, and the plasmid in this colony, termed pCPB49, was propagated and purified.

The nucleotide sequence of the insert DNA in the pCPB49 was determined in both directions by using appropriate primers according to the method described above and was analyzed with the Genetyx computer program (Software 
Development Co.). The nucleotide sequence of the C. psychrerythraea icl gene has been deposited in the DDBJ database under accession no. AB174852.

Western blot analysis

After SDS-PAGE of the purified ICLs and the cell-free extracts of the E. coli cells on $10 \%$ polyacrylamide gels (Laemmli 1970), the proteins were transferred onto a nitrocellulose membrane, Hybond-ECL (Amersham Bioscience). Western blot analysis was carried out with the ECL Western blotting detection system (Amersham Bioscience) and rabbit antibody against the purified CmICL (Watanabe et al. 2002a).

Primer extension analysis was performed as described by Sambrook and Russell (2001) with the following modifications. A synthetic 29-mer oligonucleotide, 5'-TTGAATTTGTTCTGTGCACGCATACGGGC-3', complementary to the sequence between +91 and +119 from the translation start codon of the $C$. psychrerythraea icl gene, was used as the primer. The 5'-terminal of the primer was labeled with $\left[\gamma_{-}{ }^{32} \mathrm{P}\right] \mathrm{ATP}$ and T4 polynucleotide kinase. Total RNA $(20-50 \mu \mathrm{g})$ isolated from C. psychrerythraea was incubated overnight at $42^{\circ} \mathrm{C}$ with the labeled primer in the hybridization buffer. The extension was done with a reverse transcriptase (ReverTra Ace, Toyobo). The reaction products were analyzed on a $6 \%$ polyacrylamide sequencing gel with a sequencing ladder of the C. psychrerythraea icl gene. Sequencing was performed with the T7 
Sequencing Kit (USB) with the same primer as the primer extension reaction.

Construction of expression vector for His-tagged ICL of C. psychrerythraea and 5 site-directed mutagenesis

By PCR, restriction sites for BamHI and SacI were introduced at 5'- and 3'-terminals of the ORF of C. psychrerythraea icl gene, respectively. For this purpose, the following two primers were synthesized: forward primer 5'-gcgcggatccGTCTAATTATCAGAG-3' and reverse primer 5'-gcgegagctcTTAACTGAACTGGTTAG-3'. Small letters indicate additional bases for introducing the underlined cleavage sites of the respective restriction enzymes. The amplification was carried out for 30 cycles in the DNA thermal cycler in a reaction mixture $(50 \mu \mathrm{l})$ containing $180 \mathrm{ng}$ pCPB49 as template DNA, 10 pmol each forward and reverse primer and 1 unit KOD-plus DNA polymerase in a buffer system prepared by the manufacturer. Cycling conditions were as follows: denaturation at $94^{\circ} \mathrm{C}$ for $15 \mathrm{~s}$, annealing at $50^{\circ} \mathrm{C}$ for $30 \mathrm{~s}$, and extension at $68^{\circ} \mathrm{C}$ for 2 min. After the digestion with BamHI and SacI, the PCR product was ligated to the BamHI-SacI site of pTrcHisB to obtain plasmid pHis-CpWT. Precise insertion of the $C$. psychrerythraea icl gene into the plasmid vector was verified by nucleotide sequencing.

Site-directed mutagenesis was carried out by a standard PCR method with synthetic primers (Table 1). The PCR was performed as described above. Resultant PCR products were ligated into pTrcHisB to obtain the mutated plasmids, pHisQ47K, pHisA214S, pHisA231E, pHisF333L and pHisA341N (pHisQ47K denotes pHis-CpWT introduced the substitutional mutation of Gln47 by Lys in the CpICL). The introduced mutations were checked by 
nucleotide sequencing the relevant regions of plasmids as described above.

Overexpression and purification of His-tagged ICLs

E. coli TOP10 transformed with pHis-EcWT (plasmid for His-tagged E. coli ICL), pHis-CpWT or the plasmids carrying the mutated icl genes was grown at $37^{\circ} \mathrm{C}$ in Super broth medium (12 g tryptone, $24 \mathrm{~g}$ yeast extract, $5 \mathrm{ml}$ glycerol, $3.81 \mathrm{~g} \mathrm{KH}_{2} \mathrm{PO}_{4}$ and $12.5 \mathrm{~g} \mathrm{~K}_{2} \mathrm{HPO}_{4}$ per litter ( $\left.\mathrm{pH} 7.0\right)$ ) containing $50 \mathrm{mg} / \mathrm{l}$ ampicillin until $\mathrm{OD}_{600}$ of the culture reached 0.6. The cultures were rapidly cooled on ice and were further incubated for $16-24 \mathrm{~h}$ at $15^{\circ} \mathrm{C}$ after the addition of $1 \mathrm{mM}$ isoplopyl- $\beta$-thiogalactopyranoside (IPTG) to induce the expression of His-tagged ICL proteins. Because of the marked thermolability of CPICL (Watanabe et al. 2002b), the induction of gene expression by IPTG were carried out at $15^{\circ} \mathrm{C}$. As described previously (Watanabe et al. 2004), cell-free extracts were prepared and His-tagged ICLs were then purified by column chromatography of Ni-NTA agarose (Qiagen). The purified His-tagged ICLs were concentrated with polyethylene glycol \#20,000 and dialyzed against 20 $\mathrm{mM}$ potassium phosphate ( $\mathrm{pH}$ 6.85), containing $2 \mathrm{mM} \mathrm{MgCl}_{2}, 4 \mathrm{mM}$ DL-isocitrate, $10 \%$ (v/v) glycerol and $1 \mathrm{mM}$ dithiothreitol (DTT). All His-tagged ICLs were stocked at $-35^{\circ} \mathrm{C}$ until use.

Enzyme assay

The ICL activity was assayed at $\mathrm{pH} 6.85$ by measuring the increase of absorbance at $324 \mathrm{~nm}$ due to the formation of glyoxyl-phenylhydrazone as 
described previously (Watanabe et al. 2001). The reaction mixture contained $66.7 \mathrm{mM}$ potassium phosphate buffer $\left(\mathrm{pH}\right.$ 6.85), $5 \mathrm{mM} \mathrm{MgCl}_{2}, 3.3 \mathrm{mM}$ phenylhydrazine- $\mathrm{HCl}, 2 \mathrm{mM}$ cysteine- $\mathrm{HCl}, 1.67 \mathrm{mM}$ sodium isocitrate and an appropriate amount of enzyme in a final volume of $3 \mathrm{ml}$. The reaction was started by the addition of enzyme $(50 \mu l)$ into the mixture previously equilibrated at assay temperatures. One unit of the activity was defined as the formation of $1 \mu \mathrm{mol}$ of product per min.

10 Molecular modeling of C. psychrerythraea ICL

The three-dimensional structural model of CpICL was built using ICL from $E$. coli (PDB No. 1IGW) as a homology model with a homology modeling program (www.cbs.dtu.dk/services/CPHmodels/index.php).

\section{Results}

20 Cloning of the C. psychrerythraea icl gene

By genomic PCR described in Materials and Methods, the 668 bp DNA fragment was obtained and then sequenced. The deduced amino acid sequence was consistent with the partial amino acid sequence of C. psychrerythraea ICL protein reported previously (Watanabe et al. 2002b). Genomic Southern blot analysis using this PCR product as probe revealed that about $3 \mathrm{kbp}$ of single fragment of the C. psychrerythraea genomic DNA digested with SpeI hybridizes 
with the probe. Therefore, for cloning of the icl gene, the genomic library was constructed with pBS carrying the similar size of SpeI-digests of the C. psychrerythraea genomic DNA and was screened with the same probe. A clone with strongest signal was selected and the plasmid within the clone 5 (designated as pCPB49) was purified (Fig. 1).

Nucleotide and deduced amino acid sequences of the C. psychrerythraea icl gene

Both strands of the insert DNA subcloned in the plasmid pCPB49 were sequenced (Fig. 2). This insert contained an ORF with full length of 1,587 bp, and a putative ribosome-binding site (Shine and Dalgano 1974), GGAG, was found 7-10 bases upstream of the ATG codon. The ORF encodes a polypeptide of 528 amino acids, and the molecular mass was calculated as $58,131 \mathrm{Da}$. This value was compatible with that of the purified ICL from this bacterium estimated by gel filtration (homotetramer of the $60 \mathrm{kDa}$ subunit) (Watanabe et al. 2002b). Previously, we reported that bacterial ICLs can be classified into two phylogenetic groups, subfamilies 1 and 3, based on their amino acid sequences (Watanabe et al. 2004). The deduced amino acid sequence showed 24-29\% identities with subfamily 1 ICLs from many bacteria, including the E. coli ICL ( $28 \%$ identity). On the other hand, sequence identities with subfamily 3 ICLs shown in Fig. 3 were $70 \%$ or above, except for the Hyphomicrobium methylovorum ICL (54\% identity). In particular, the sequence identity to the

25 ICL of C. maris, another psychrophilic bacterium of the same genus Colwellia, attained to $88 \%$. 
Expression of the C. psychrerythraea icl gene

Expression of the C. psychrerythraea icl gene in the icl-defective mutant of $E$. 5 coli, ACA421, was examined under several conditions by Western blot analysis. As Watanabe et al. (2002b) reported previously, antibody against the purified CmICL cross-reacted with the ICL protein purified from the C. psychrerythraea cells, but not with the E. coli ICL. Whereas no protein cross-reactive with this antibody was present in crude extract of the E. coli ACA421 cells transformed with a control vector, $\mathrm{pBS}$, a major cross-reactive protein band was detected at the same position as the purified CPICL in crude extract of the E. coli transformant cells carrying pCPB49 grown at 15 and $25^{\circ} \mathrm{C}$ on $\mathrm{LB}$ medium. These results demonstrate that the C. psychrerythraea icl gene is cloned in this plasmid. ICL is known to be highly induced in microorganisms grown on acetate (Vanni et al. 1990). When the E. coli transformant cells carrying pCPB49 were grown at 15 and $25^{\circ} \mathrm{C}$ on $\mathrm{LB}$ medium supplemented by $50 \mathrm{mM}$ sodium acetate, the gene expression was induced. Furthermore, irrespective of the supplementation of sodium acetate in growth medium, the expression level of this gene in the E. coli mutant grown at $15^{\circ} \mathrm{C}$ was larger than that grown at $25^{\circ} \mathrm{C}$, and no expression were detected when it was grown at $37^{\circ} \mathrm{C}$. Similar results were obtained by the assay of ICL activity in the crude extract of E. coli ACA421 cells transformed with pCPB49 (Table 2). These results were in accord with those of Northern and Western blot analyses carried out using the intact cells of C. psychrerythraea (Watanabe et al. 2002b), indicating that the expression of C. psychrerythraea icl gene is not only acetate-inducible but also cold-inducible and that the insert DNA subcloned in the plasmid pCPB49 contains ORF of the icl gene and its complete promoter region. 
Analysis of 5'-terminal region of the C. psychrerythraea icl mRNA

5 The 5'-end of the C. psychrerythraea icl mRNA was examined by primer extension analysis (Fig. 4). The result revealed that transcriptional start site of the C. psychrerythraea icl gene (TS site in Fig. 4) is guanine, located at 87 bases upstream of translational initiation codon. Furthermore, the putative -35 and -10 promoter elements, TTCCTA and TATTAT, were found 32 and 8 bases upstream of the TS site, respectively (Fig. 2).

Site-directed mutagenesis of CpICL and properties of mutated ICLs

Cold-adapted enzymes should possess inherent characteristics on protein structure responsible for the common properties, high catalytic function at low temperature and marked thermolability, compared with mesophilic and/or thermophilic counterparts. The introduction of suitable mutation(s) to these enzymes is one of useful approaches for studying this problem. From multiple alignment of amino acid sequences of subfamily 3 ICLs from several mesophilic and psychrophilic bacteria, several substitutions of amino acid residues common to the two cold-adapted ICLs, CpICL and CmICL, were found to exist in highly conserved regions of the ICL proteins (Fig. 3). Among them, Gln47 (the 47th Gln residue from N-terminal), Ala214, Ala231, Phe333 and Ala341 of the CpICL (shown by stars in Fig. 3) were substituted for the conserved amino acid residues of other ICLs by site-directed mutagenesis as described in Materials and Methods. 
To examine a possibility that His-tagging of the enzyme at the N-terminal alters its original properties, the activity of His-tagged CpICL (Cp-WT) was assayed at various temperatures (Fig. 5). The purified $C p$-WT showed the maximum activity at $25^{\circ} \mathrm{C}$ and its kcat value at this temperature was $28.5 \mathrm{~s}^{-1}$.

5 These results were consistent with those of the native CPICL reported previously $\left(25^{\circ} \mathrm{C}\right.$ and $27.7 \mathrm{~s}^{-1}$, respectively; Watanabe et al. 2002b). In addition, as well as the native $C p I C L$ and $C m I C L$, the $C p$-WT activity could not be measured exactly at $30^{\circ} \mathrm{C}$ because the enzyme was rapidly inactivated at this temperature even during the enzyme assay. These indicate that the His-tagging at the $\mathrm{N}$-terminal does not affect the activity and characteristics of CpICL.

The activities of recombinant CpICLs and His-tagged E. coli ICL (Ec-WT) at various temperatures were shown in Fig. 5. The ICL activity of F333L, which is CpICL substituted Phe333 by Leu, was not able to be exactly measured because of its very low activity, suggesting that Phe333 of the CpICL is important for the catalytic function. Temperature dependence of ICL activities of Q47K and $\mathrm{A} 341 \mathrm{~N}$ was similar to that of $C p-\mathrm{WT}$. Furthermore, as well as $C p$-WT, optimum temperature for the two enzyme activities was $25^{\circ} \mathrm{C}$, and their exact activities could not be measured at $30^{\circ} \mathrm{C}$ because they were rapidly inactivated even during the enzyme assay at this temperature. At the optimum temperature, the activity of Q47K ( $k$ cat value, $26.6 \mathrm{~s}^{-1}$ ) was comparable to that of $C p$-WT, but A341N (13.3 s s) exhibited lower activity than $C p$-WT. The ICL activities of A231E below $20^{\circ} \mathrm{C}$ were similar to those of $\mathrm{A} 341 \mathrm{~N}$, but the former enzyme showed the maximum activity at $20^{\circ} \mathrm{C}$. Further lowering of ICL activity at low temperatures was observed in A214S, but optimum temperature for this enzyme activity increased by about $5^{\circ} \mathrm{C}$, compared to that of $\mathrm{Cp}$-WT. However, above $30^{\circ} \mathrm{C}$, this enzyme was also rapidly inactivated. These results imply that Ala214 of the CpICL is involved in its high activity at 
low temperatures.

To estimate whether the mutations of CmICL affect the thermal stability, the residual activities of wild and mutated enzymes after the incubation for various times at $25^{\circ} \mathrm{C}$ were examined (Fig. 6). A214S and A231E were more 5 thermostable and more thermolabile than $C p$-WT, respectively.

\section{Discussion}

10 In this study, the icl gene encoding the cold-adapted ICL of C. psychrerythraea was cloned and sequenced. From expression analysis, DNA fragment cloned in the plasmid pCPB49 was confirmed to contain the ORF of this gene and full length of the promoter region, because the expression of this gene in the E. coli cells was induced by acetate and low temperature and this result was consistent with that in the C. psychrerythraea cells reported previously (Watanabe et al. 2002b). The CCAAT sequence is present in the upstream region of the $C$. maris icl gene whose expression is induced by acetate and low temperature as well as the C. psychrerythraea icl gene (Watanabe et al. 2002a). This sequence has been reported to be cis-acting element for cold-inducible expression of several genes including the icd-II encoding the cold-adapted isocitrate dehydrogenase isozyme II of C. maris (Qoronfleh et al. 1992; Sahara et al. 1999). Furthermore, several cis-acting elements for cold-inducible gene expression was found by promoter analysis of the genomic DNA of a Gram-negative psychrophilic bacterium, Pseudomonas haloplanktis strain TAC125, which are about $20 \mathrm{bp}$ of upstream AT-rich sequences adjacent to the -35 consensus element of promoters (Duilio et al. 2004). However, such sequences are absent in the upstream region of the C. psychrerythraea icl gene 
despite its cold-inducible expression (Fig. 2). Therefore, it is suggested that other novel cis-element is involved in the cold-inducible expression of this gene or the stabilization of its mRNA at low temperature influences the gene expression as reported for $\operatorname{csp} A$ and otsA/B mRNA of E. coli (Tanabe et al. 1992;

5 Kandror et al. 2002).

From the comparison of amino acid sequence with various bacterial ICLs, it was found that the CpICL belongs to subfamily 3, as well as the CmICL (Fig. 3). As reported previously (Watanabe et al. 2002a), six additional short insertions of 3-36 amino acids are scattered in the CmICL, compared to subfamily 1 ICLs from E. coli and Mycobacterium tuberculosis. The same insertions were also present in the CpICL. In spite of such a sequential difference between the CmICL and E. coli ICL, many amino acid residues essential for catalytic function and for binding with substrates and divalent metal ion, which were identified in the E. coli ICL, are conserved in the CmICL (Watanabe et al. 2002a). In this study, these amino acid residues of the CmICL were found to be completely conserved in the CpICL.

Multiple alignments of amino acid sequences of subfamily 3 ICLs and the putative ones from several bacteria, including the cold-adapted CPICL and CmICL, revealed that several substitutions of amino acid residues peculiar to these two enzymes are present in the conserved regions of the ICL proteins. From the following reasons, five amino acid residues of Gln47, Ala214, Ala231, Phe333 and Ala341 were selected and were substituted by point mutations; Gln47, the corresponding amino acid residues of other ICLs are basic Lys or Arg; Ala214, in a three-dimensional model of the CpICL protein constructed with the homology modeling program, this residue is located closely to TIM barrel structure involved in the binding of substrate (Britton et al. 2001), and the corresponding residue is more hydrophilic Ser in other ICLs; Ala231 and 
Phe333, the corresponding residues are acidic Glu or Asp and less hydrophobic Leu in most of other ones, respectively; Ala341, the corresponding residues of other ones are Asn. Although the A214S mutation of CpICL led to lowering of the enzyme activity, the thermostability and optimum temperature for ICL activity of the mutated enzyme were elevated, compared to those of wild-type enzyme. These results indicate that Ala214 is involved in thermolability of the CPICL and its high activity at low temperatures. Possible hydrogen bonds of this residue predicted by a program SWISSPDB VIEWER were shown in Fig. 7. The mutated ICL, A214S, can form two hydrogen bonds between main chain of the substituted Ser214 and side chain of Gln119, and side chain of Ser214 and main chain of Gln119, whereas only one hydrogen bond is allowed between main chain of native Ala214 and side chain of Gln119 in the Cp-WT. Therefore, this may be responsible for the decrease of structural flexibility of the A214S and resultant increase of its thermostability. On the other hand, the decreased thermostability and lowering of catalytic activity were observed in the A231E, and Q47K and A341N, respectively. These three substitutions of amino acid residues have negative effects to thermostability and specific activity of CpICL, suggesting that these amino acid residues are also involved in the thermostability and catalytic activity of CpICL. In particular, the F333L mutation of CPICL resulted in almost complete loss of its catalytic function, implying that Phe333 might play an important role for catalytic function of this enzyme. Furthermore, various combinations of these amino acid substitutions may be able to bring some different effects on the psychrophilic properties of CPICL. On the other hand, it was reported that the surface of cold-adapted enzyme tends to have more nonpolar amino acid residue, in particular Ala, compared with the corresponding mesophilic and thermophilic ones (Siddiqui and Cavicchioli 2006; Sælensminde et al. 2007). Besides A214, A231 and 
A341, several substitutions by Ala are found to be still present in the two cold-adapted CpICL and CmICL (Fig. 3). Some of such Ala residues might be responsible for the psychrophilic nature of these enzymes. Thus, further studies are planned to clarify the role of these residues of cold-adaptation and 5 thermolability of the CPICL.

Acknowledgements We sincerely thank Dr. Isao Yumoto of the National Institute of Advanced Industrial Science and Technology for the donation of $C$. psychrerythraea. 


\section{References}

Britton KL, Abeysinghe IS, Baker PJ, Barynin V, Diehl P, Langridge SJ, McFadden BA, Sedelnikova SE, Stillman TJ, Weeradechapon K, Rice DW (2001) The structure and domain organization of Escherichia coli isocitrate lyase. Acta Cryst D57:1209-1218

Cavicchioli R, Siddiqui KS, Andrews D, Sowers KR (2002) Low-temperature extremophiles and their applications. Curr Opin Biotechnol 13:253-261

Cozzone AJ (1998) Regulation of acetate metabolism by protein phosphorylation in Escherichia coli. Annu Rev Microbiol 52:127-164

D'Aoust JY, Kushner DJ (1972) Vibrio psychroerythrus sp. n.: classification of the psychrophilic marine bacterium, NRC 1004. J Bacteriol 111:340-342

Deming JW, Somers LK, Straube WL, Swartz DG, Macdonell MT (1988) Isolation of an obligately barophilic bacterium and description of a new genus, Colwellia gen. nov. Syst Appl Microbiol 10:152-160

Duilio A, Madonna S, Tutino ML, Pirozzi M, Sannia G, Marino G (2004) Promoters from a cold-adapted bacterium: definition of a consensus motif and molecular characterization of UP regulative elements. Extremophiles $8: 125-132$

Fields PA, Somero GN (1998) Hot spots in cold adaptation: localized increases in conformational flexibility in lactate dehydrogenase A4 orthologs of Antarctic notothenioid fishes. Proc Natl Acad Sci U S A 95:11476-11481

Gerday C, Aittaleb M, Arpigny JL, Baise E, Chessa JP, Garsoux G, Petrescu I, Feller G (1997) Psychrophilic enzymes: a thermodynamic challenge. Biochim Biophys Acta 1342:119-131

Geolette D, Damien B, Blaise V, Depiereux E, Uversky VN, Gerday C, Feller G (2003) Structural and functional adaptation to extreme temperatures in 
psychrophilic, mesophilic, and thermophilic DNA ligase. J Biol Chem 278: 37015-37023

Ishii A, Suzuki M, Sahara T, Takada Y, Sasaki S, Fukunaga N (1993) Gene encoding two isocitrate dehydrogenase isozymes of a psychrophilic bacterium, Vibrio sp. strain ABE-1. J Bacteriol 175:6873-6890

Kandror O, Deleon A, Goldberg AL (2002) Trehalose synthesis is induced upon exposure of Escherichia coli to cold and is essential for vaiability at low temparatures. Proc Natl Acad Sci U S A 99:9727-9732

Kenan C (1998) Use of bacteriophage lambda recombination function to promote gene replacement in Escherichia coli. J Bacteriol 180:2063-2071

Kornberg HL, Krebs HA (1957) Synthesis of cell constitutents from $\mathrm{C}_{2}$-units by a modified toricarboxilic acid cycle. Nature 179:988-991

Kornberg HL (1966) The role and control of the glyoxylate cycle in Escherichia coli. Biochem J 99:1-11

Laemmli UK (1970) Cleavage of structural proteins during the assembly of the head of bacteriophage T4. Nature 227:680-685

Qoronfleh MW, Debouck C, Keller J (1992) Identification and characterization of novel low-temperature-inducible promoters of Escherichia coli. J Bacteriol 174:7902-7909

Sælensminde G, Halskau Jr Ø, Helland R, Willassen NP, Jonassen I (2007) Structure-dependent relationships between growth temperature of prokaryotes and the amino acid frequency in their proteins. Extremophiles 11:585-596

Sahara T, Suzuki S, Tsuruha J, Takada Y, Fukunaga N (1999) cis-Acting elements responsible for low-temperature-inducible expression of the gene coding the thermolabile isocitrate dehydrogenase isozyme of a psychrophilic bacterium, Vibrio sp. Strain ABE-1. J Bacteriol 181:2602-2611

Sambrook J, Russell D (2001) Molecular Cloning: a laboratory manual, 3rd edn. 
Cold Spring Harbor Laboratory, Cold Spring Harbor, NY

Shine J, Dalgano L (1974) The 3'-terminal sequence of Escherichia coli 16S ribosomal RNA: complementarity to nonsense triplets and ribosome binding sites. Proc Natl Acad Sci U S A 71:1342-1346

5 Siddiqui KS, Cavicchioli R (2006) Cold-adapted enzymes. Annu Rev Biochem $75: 403-433$

Takada Y, Ochiai T, Okuyama H, Nishi K, Sasaki S (1979) An obligatory psychrophilic bacterium isolated on the Hokkaido coast. J Gen Appl Microbiol 25:11-19

Tanabe H, Goldstein J, Yang M, Inouye M (1992) Identification of the promoter region of the Escherichia coli major cold shock gene, cspA. J Bacteriol $174: 3867-3873$

Vanni P, Giachetti E, Pinzauti G, McFadden BA (1990) Comparative structure, function and regulation of isocitrate lyase, an important assimilatory enzyme. Comp Biochem Physiol 95B:431-458

Watanabe S, Takada Y, Fukunaga N (2001) Purification and characterization of a cold-adapted isocitrate lyase and a malate synthase from Colwellia maris, a psychrophilic bacterium. Biosci Biotech Biochem 65:1095-1103

Watanabe S, Takada Y, Fukunaga N (2002a) The cold-inducible icl gene encoding thermolabile isocitrate lyase of a psychrophilic bacterium, Colwellia maris. Microbiology 148:2579-2589

Watanabe S, Yamaoka N, Fukunaga N, Takada Y, (2002b) Purification and characterization of a cold-adapted isocitrate lyase and expression analysis of the cold-inducible isocitrate lyase gene from the psychrophilic bacterium Colwellia psychrerythraea. Extremophiles 6:397-405

Watanabe S, Takada Y (2004) Amino acid residues involved in cold adaptation of isocitrate lyase from a psychrophilic bacterium, Colwellia maris. 
Microbiology 150:3393-3403

Yumoto I, Kawasaki K, Iwata H, Matsuyama H, Okuyama H (1998) Assignment of Vibrio sp. strain ABE-1 to Colwellia maris sp. nov., a new psychrophilic bacterium. Int J Syst Bacteriol 48:1357-1362. 
Table 1 Oligonucleotides used in site-directed mutagenesis

\begin{tabular}{|c|c|c|c|c|}
\hline \multirow{3}{*}{5} & \multirow{3}{*}{$\frac{\text { Plasmid }}{\text { pHisQ47K }}$} & \multirow{3}{*}{$\begin{array}{r}\text { Substitution } \\
\text { Gln47 } \rightarrow \text { Lys }\end{array}$} & \multicolumn{2}{|r|}{ Primers } \\
\hline & & & forward & 5'-GGTCTAGAGATAGCTAAGTACACTGCAG-3' \\
\hline & & & reverse & 5'-CTGCAGTGTACTTAGCTATCTCTAGACC-3' \\
\hline \multirow{4}{*}{10} & pHisA214S & Ala214 $\rightarrow$ Ser & forward & 5'-CGAAAACCAAGTATCTGATGAAAAGC-3' \\
\hline & & & reverse & 5'-GCTTTTCATCAGATACTTGGTTTTCG-3' \\
\hline & pHisA231E & Ala231 $\rightarrow$ Glu & forward & 5'-GTAACTGTTCCTCATGAAGATTTCCACTC-3' \\
\hline & & & reverse & 5'-GAGTGGAAATCTTCATGAGGAACAGTTAC-3' \\
\hline \multirow[t]{4}{*}{15} & pHisF333L & Phe333 $\rightarrow$ Leu & forward & 5'-GAGCGTTGTGTACTTGACTGTATCGGTGC-3' \\
\hline & & & reverse & 5'-GCACCGATACAGTCAAGTACACAACGCTC-3' \\
\hline & pHisA341N & Ala341 $\rightarrow$ Asn & forward & 5'-CGGTGCACTTAATAATGGCGCTGATTTAC-3' \\
\hline & & & reverse & 5'-GTAAATCAGCGCCATTATTAAGTGCACCG-3' \\
\hline
\end{tabular}

The underlined letters indicate the codons of amino acid residues substituted by site-directed mutagenesis. 
Table 2 ICL activity of E. coli icl-defective mutant transformed with the C. psychrerythraea icl gene

\begin{tabular}{lccc}
\cline { 2 - 3 } Growth medium & $37^{\circ} \mathrm{C}$ & $25^{\circ} \mathrm{C}$ & $15^{\circ} \mathrm{C}$ \\
\hline LB & $1.40 \times 10^{-3}$ & $2.08 \times 10^{-3}$ & $6.07 \times 10^{-3}$ \\
LB + acetate & $3.72 \times 10^{-3}$ & $7.29 \times 10^{-3}$ & $1.70 \times 10^{-2}$ \\
\hline
\end{tabular}

The values indicate ICL activity (unit/mg protein) in crude extract of E. coli ACA421 transformed with pCPB49. The enzyme activity was assayed at $25^{\circ} \mathrm{C}$. The E. coli transformant was grown on LB medium supplemented with none (LB) or $1550 \mathrm{mM}$ sodium acetate ( $\mathrm{LB}+$ acetate). No ICL activity was detected in the E. coli ACA421 cells grown at $37^{\circ} \mathrm{C}$ on $\mathrm{LB}$ or LB + acetate medium. 


\section{Legends to figures}

Fig. 1 Physical and restriction map of the genomic DNA fragment containing the C. psychrerythraea icl gene. The black bar indicates the 668 bp DNA 5 fragment used as the probe for colony hybridization.

Fig. 2 Nucleotide and deduced amino acid sequences of the C. psychrerythraea icl gene. The underlined sequences are the putative -35 and -10 promoter elements. The boxed nucleotides are the putative Shine-Dalgarno sequence. The guanine in black box indicates transcriptional start point (Fig. 5). The probable stem-loop structures located downstream of the translational stop codon are shown by two opposite arrows.

Fig. 3 Alignment of amino acid sequences of subfamily 3 ICLs from various 15 bacteria. Amino acid residues identical and similar to those of CpICL are shown as white letters in black boxes and black letters in gray boxes, respectively. Gaps in the alignments are indicated by dashes. C.m., C. maris (accession no. for the protein database, BAB62107), H.m., Hyphomicrobium. methylovorum GM2 (BAA23678), and R.e., Ralstonia. eutropha (AAM18124). Putative ICLs, R.m., Ralstonia metallidurans (ZP_00022497), R.p., Rhodopseudomonas palustris (ZP_00009157), B.j., Bradyrhizobium japonicum (NP_709695), N.a., Novosphingobium aromaticivoruns (ZP_0093836), P.a., Pseudomonas aeruginosa PAO1 (NP_251324), A.v., Azotobacter vinelandii (ZP_00091825), and A.c., Acinetobacter calcoaceticus ADP1 (YP_045792).

25 Stars on the sequences indicate the positions of amino acid residues substituted by site-directed mutagenesis (see text). 
Fig. 4 Primer extension analysis. Product of primer extension with a primer complementary to $i c l$ is shown in lane 1 . Total RNA $(35 \mu \mathrm{g})$ was isolated from the C. psychrerythraea cells grown at $15^{\circ} \mathrm{C}$ on nutrient medium containing 50 $\mathrm{mM}$ acetate and was used as the template. The sequence ladders are shown in 5 lanes T, G, C and A.

Fig. 5 Effect of temperature on activities of wild and mutated ICLs.

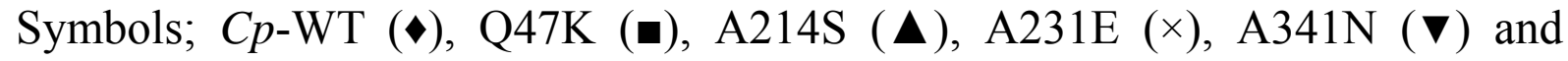
$E c$-WT $(\bullet)$. The $k$ cat values of ICLs were measured under standard assay condition.

Fig. 6 Thermostability of wild and mutated ICL activities. Symbols used in this figure are the same as Fig. 6 . The purified enzymes were dialyzed at $4^{\circ} \mathrm{C}$ against $20 \mathrm{~mm}$ potassium phosphate $\left(\mathrm{pH}\right.$ 6.85) containing $2 \mathrm{mM} \mathrm{MgCl} \mathrm{M}_{2}$ and 1 $\mathrm{mM}$ DTT. After the incubation for the indicated time periods at $25^{\circ} \mathrm{C}$, the dialyzed enzymes were withdrawn and immediately cooled for $10 \mathrm{~min}$ on ice. The ICL activities were then measured at optimum temperatures of the respective enzymes.

Fig. 7 Molecular models of $C p-\mathrm{WT}$ and A214S. The models were built by the homology modeling program. The main chains and side chains of Gln119 and Ala214 or Ser214 are indicated by red and orange, respectively. Hydrogen bonds predicted by a program SWISSPDB VIEWER is indicated by green dashes. 

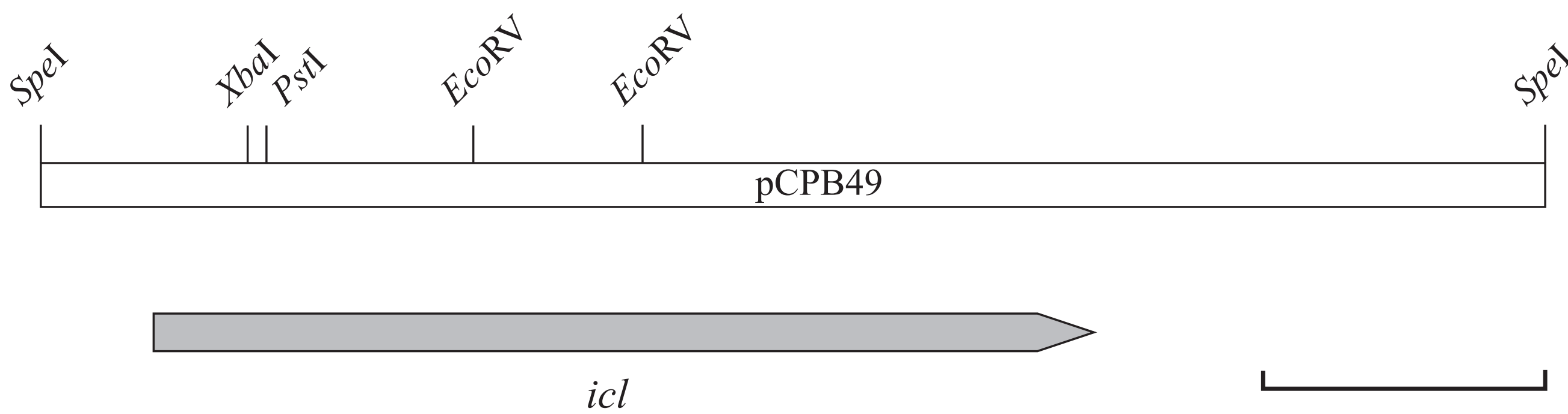

probe

Fig. 1 Sato et al 


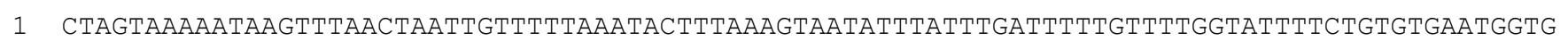

91 GTAATCATCACTATATATTTCCTAAATACATGGTTAGTAGACTATTATTTTTGCT $\frac{\mathbf{G} \text { TCTAGTGCGAAGACTTAAAAAGTCTGTTACACCA }}{-10}$ 180

181 ACCAAGCTAATAtAgCTTTTATATACTACAAACAAAgTAAATGGAGATTGATATGTCTAATTATCAGAGTGCAATAGAAGCAGTTCAAGC 270 $\begin{array}{llllllllllllllllllllllllllll}\text { SD } & M & S & N & Y & \& & S & A & I & E & A & V & \& & A\end{array}$

271 GATCAAAGCAAAAGCCGGTAGCTCTTGGGATGCTATAAACCCAGAATCAATTGCCCGTATGCGTGCACAGAACAAATTCAAAACTGGTCT 360 $\begin{array}{lllllllllllllllllllllllllllllllll}I & K & A & K & A & G & S & S & W & D & A & I & N & P & E & S & I & A & R & M & R & A & Q & N & K & F & K & T & G & L\end{array}$

361 AgAGATAGCTCAGTACACTGCAGACATTATGCGTGCTGATATGGCTGCATTTGATGCAGACAAGACTCAATATACACAATCTCTAGGTTG

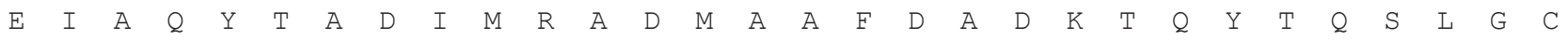

451 TTGGCATGGTTTTGTTGGCCAACAAAAAATGATTTCTATCAAAAAACATTTTGATGGTAAAACAGACCGTCGTTATTTATATCTTTCAGG

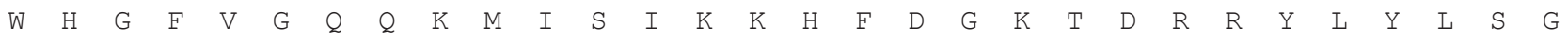

541 TTGGATGGTTGCTGCACTTCGCAGTGAATTTGGTCCTCTTCCTGATCAATCTATGCATGAAAAAACGTCGGTAGCCTCTTTAGTTGCTGA

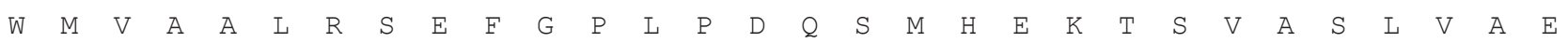

631 GCTTTATACTTTCTTACGTCAAGCTGACGCACGTGAATTAGGCGGTCTTTTCCGTGAACTAGATGCAGCTGCTGAAGGTGATAAAGCTGC

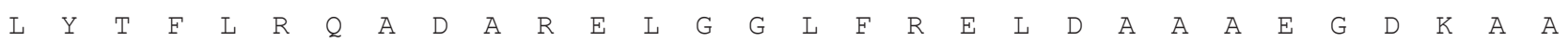

721 TATCCAATCACAGATTGATAACCATGTTACTCACGTTGTGCCAATTGTTGCTGATATCGATGCTGGTTTTGGTAACGCTGAAGCGACTTA $\begin{array}{llllllllllllllllllllllllllllllllllllllllll}I & Q & S & Q & I & D & N & H & V & T & H & V & V & P & I & V & A & D & I & D & A & G & F & G & N & A & E & A & T & Y\end{array}$

811 CTTAATGGCTAAGCAAATGATTGAAGCAGGTGCTTGTGCGCTTCAAATCGAAAACCAAGTAGCTGATGAAAAGCAATGTGGTCATCAAGA

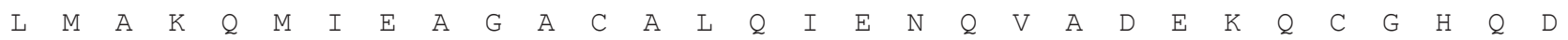

901 TGGCAAAGTAACTGTTCCTCATGCTGATTTCCACTCTAAAATTCGTGCATTACGCCATGCATTTTTAGAACTAGGTATAGACAACGGTCT

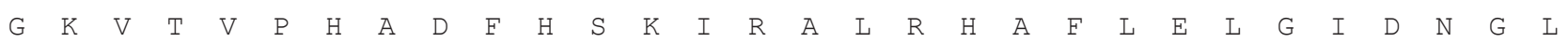

991 TATCGTTGCACGTACTGACTCTGAAGGTGCTGGTTTGACTAAAGAAATCGCTGTTGTTAAAGAGCCTGGTGATTCTGGCGATATCTATAA 1080

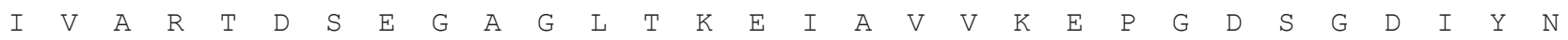

1081 CTCTTATTTAGATGTTGAAGAAATCAGCGCAGCTGATATGGCTGAAGGCGATGTATGCTTTAATCGTGACGGTAAATTAGTTCGTCCTAA

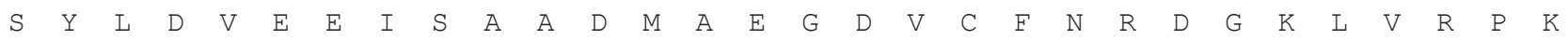

1171 GCGTTTACCTTCAGGTTTATACCAATTCCGTCAAGGTACTGGTCATGAGCGTTGTGTATTTGACTGTATCGGTGCACTTAATGCTGGCGC 1260

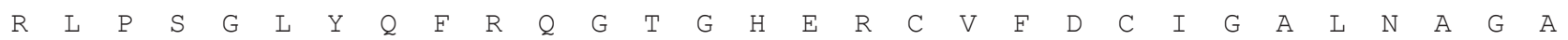

1261 TGATTTACTTTGGATTGAAACGGCAGTGCCAACGGTACACGAAATTGCTGGTATGATGGATGACGTTCGTAAAGTTCACCCAGATGCGAA

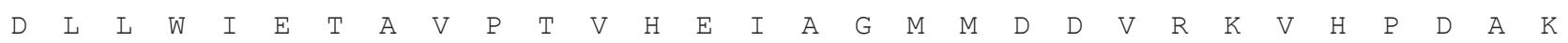

1351 ACTTGTTTATAACAACTCTCCATCTTTTAACTGGACACTTAATTTCCGTCAGCAAGCATATGACGCAATGGTTGAAGCGGGTCAAGATGT

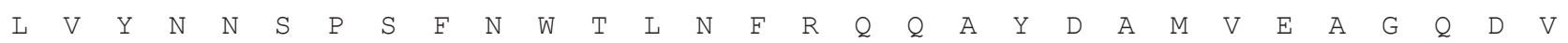

1441 ATCTGCATACGTTCGTGCTGACTTAATGAAAGCTGAATATGACGAAACTGAATTGTCTGCAACAGCTGATGAACGCATTCGTACTTTCCA

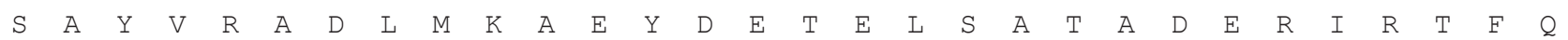

1531 AGCTGATACTGCACGTGAAGCGAACGTATTCCATCACTTAATCACTTTACCTACTTACCATACAACTGCGTTATCAGTAGATAACTTAGC

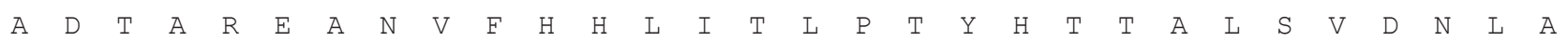

1621 TAAAGAGTACTTCGGTGAGCAAGGGATGCTTGGTTATGTTAAAGGTGTACAACGTAAAGAAATCCGTCAAGGTATTGCCTGTGTTAAACA

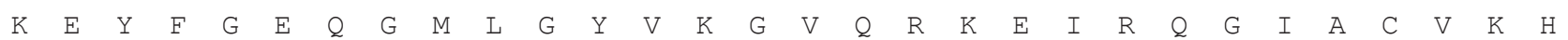

1711 TCAAAACATGTCTGGTTCAGACATGGGTGATGATCACAAAGAATACTTTGCAGGTGAAAATGCACTTAAAGCGGGTGGCGCAAAAAATAC

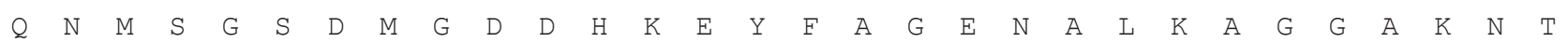

1801 GTCTAACCAGTTCAGTTAATCACCAATATTTTAATCTCTTAAGTGTTGCTTAAGGCTGAAATATAAATACGAATCAGATTGTTACTAACG $S \quad N \quad Q \quad F \quad S$ *

1891 TAGCAATCTGATTTTTTTTGTTAAAAAATAGTATTGTAATTGTAAATTAGTTTACTAGAATCAAGAGAACAAACTAAACAGTTTACACTT

1981 TGAAACAATtGTGCTATATTGTTTTGATCGTTCGATAAATAAATACATGCCTGATTTTTACTACTTTTGTACGAAGGAAATATGTTGCA

2071 GTCATCTTCATCTAAACAATTGTTGCTACTTAATACCAATGCTGAAAGGCTTACTAAACTTGAAAACTTATTACTTTCTGGCACCCGCTA 
C. p .

C. m.

R.e

R. $\mathrm{m}$

A. V

P. a.

B.j

$R \cdot p$

N. a

A.C

H. $\mathrm{m}$.

C. p .

C.m

R.e

R. $\mathrm{m}$.

A. v

B.j.

R. $\mathbf{p}$

N.

A. C

H. $\mathrm{m}$.

C. $p$

C.m

R.e

R. $\mathrm{m}$.

A. $v$

P. a

B.j

R.p

$N$ a

121

205 CALQIENQVADEKQCGHQDGKVTVPHADFHSK IRALRHAFLELGIDNGLIVARTDSEGAGLTKEIAVVKEPGDSGDIYNSYLDVEEISAA
205 CALQI ENQVADEKQCGHQDGKVTVPHADFHSKI RALRHAFLELGIDNGIIVSRTDSEGAGLTKEIAVVKEPGDQGDIYNSFLDVEEIDVS

204 CCIQIENQVSDEKQCGHQDGKVTVPHEDFLAKIRAIRYAFLELGVDDGIIVARTDSLGAGLTKQIAVTNTPGDLGDQSNYF LACEELSAD

R.m. 204 CCIQIENQVSDEKQCGHQDGKVTVPHEDFLAKIRAIRYAFLELGVDDGVIVARTDSLGAGLTKQIAVTATPGDLGDQYNSFLDCEELSAD

A.V. 208 CCIQI ENQVSDEKQCGHODGKVTVPHEDFLAK INAVRYAF LELGVDDGVIVARTDSLGAGLTKQ I AVTRQEGDLGDKYNAF LDCEEISPA

P.a. 208 CCIQI ENQVSDEKQCGHQDGKVTVPHIDFLAKINAVRYAFLELGVDDGVIVARTDSLGAGLTKOIAVTNEPGDLGDLYNSFLDCEEISES

B . j . 269 CALQI ENQVSDEKQCGHQDGKVTVPHDVF LAK I RACRHAF LELGVEDGVVVTRTDSIGAGLTQQ I AVSHKPGDIGDQYNSFLDCEEITAE

R.p. 221 CALQIENQVSDEKQCGHQDGKVTVPHDVFTAKVRAIRHAF LEMGVEDGITVTRTDSLGAGLTQQIAVSHQPGDIGDQYNSFLDCEEVDAS

$\begin{array}{lll}\text { N.a. } & 207 & \text { CCIQIENQVSDEKQCGHQDGKVTVPHEDFIAKIRAVRYAFMELGVDDGVIVARTDSIGAGLTKQIAFVKEPGDIGDQYNSFLDCEEVDAA }\end{array}$

A.C. 207 CAIQI ENQVSDAKQCGHQAGKVTVPHEDFLAK INAVRYAF LELGVDEGVIVARTDSEGADLTQKIPVSKEKGDLASQYISYLDTQEID I A

H.m. 211 CCLQIENQVSDAKQCGHQDGKVTVPREDFIEKLRACRLAFEELGVDDGVIVARTDSLGASTQKIPVSQQAGDFASSIKWLKTEPITDA

C.p. 295 D-MAEGDVCF NRDGKLVRPKRLPSGLYOFROGTGHERCVFFCTGALNÄG-ADLLWIETAVPTVHEIAGMMDDVRKVHPDAKLVYNNSPSF

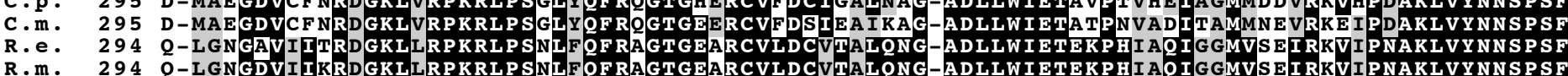

R.m. 294 Q-LGNGDVIIKRDGKLLRPKRLPSNLFQFRAGTGEARCVLDCVTALQNG-ADLLWIETEKPHIAQI GGMVSEI RKVIPNAKLVYNNSPSF

A . V . 298 E-MKNGDVVLNRNGKLLRPKRLASGLFQFRKGTGEDRCVLDCITSLQNG-ADLLWIETEKPHIGQIKGMVDRIREAIPNAKLVYNNSPSF

P.a. 298 E-LGNGDVVIKREGKLLRPKRLASNLFQFRKGTGEDRCVLDCITSLQNG-ADLLWIETEKPHVGQIKAMVDRIREVIPNAKLVYNNSPSF

B.j. 359 N-ARNGDVIINRNGKMMRPKRLPSNLYQFRPGTGEDRCVLDCITSLQNG-ADLLWIETEKPHIEQIAKMVDRIREVVPNAKLAYNNSPSF

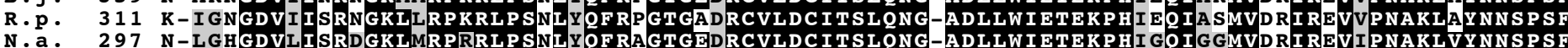

N. . 297 N-LGHGDVLISRDGKLMRPRRLPSNLYQFRAGTGEDRCVLDCITSIQNG-ADLLWIETEKPHIGQIGGMVDRIREVIPNAKLVYNNSPSF

$\begin{array}{llll}\text { A.C. } & 297 & \text { D-AQEDEILIKRDGKLHRPTRLASGLYQFREGTQHDRVVLDCVTSLQNG-ADMIWIETPTPDVAGIAGFVNDIKKQVPNAKLVYNNSPSF } \\ \text { H.m. } & 301 \text { NPLSEGELAIWQSGNFARPIRMPNGLFSFREGTGRARVIEDCIASLKDGDADIIWIETDTPNVDEIASMVAEIRKQVPDAKLVYNNSPSF }\end{array}$

C . P . 383 NWTLNF RQQAY DAMVEAGQDVSAYVRA- - DLMKAEYDETELSATADERI RTFQADTAREANVFHHL I TLPTYHTTALSVDNLAREY FGE

C.m. 383 NWTLNFRQQAFDTMVAEGKDVSSYVRA--DLMNVDYDTTELAAAADDKIRSFQADTAREAGIFHHLITLPTYHTAALSTDNLAKEYFGDA

R.e. 382 NWTLNFRQQAYDAMKAAGKDVSAYDRA--QLMSVEY DQTELAKLADGKI RTFQGDASREEGIFHHLITVATYHNAALSTDNLAKEY FGDQ

R.m. 382 NWTLNFRQQAYDAMKAAGKDVSAYERT--QLMSVEYDDSELAKIADEKIRTFQADASREAGIFHHLITLPTYHTAALSTDNLAKEYFGDQ

A. v 386 NWTLNFRQQVFDTWAAEGKDVAKYDRA- -KLMSVEYDETELALEADARI RTFQRDAAAOAGIFHHLITLPTYHTAALSTDNLAKGYFAEE

$\begin{array}{ll}\text { A. . } & 386 \text { NWTLNFRQQVFDAFVAEGKDVSAYDRN--KLMSVEYDDTELAKVADEKI RTFQRDGSAHAGIFHHLITLPTYHTAALSTDNLAKGYFADE }\end{array}$

B.j. 447 NWTLNF RWOVYDAMKEAGKDVSRYNRA--ELMKAEYDDTPLAKEADERI RTF QADSAKRAGIFHHLI TLPTYHTAALSTDNLAREY FGEQ

R.P. 399 NWTLNFRWQVYDAWKEEGKDVSKYNRA--ELMKAEYDETPLAIEADARIRTFQADSAKRAGIFHHLITLPTYHTAALSTDNLAREYFGDQ

N.a. 385 NWTLNF ROQVFDAWQAEGRDTSAYDRA- -KLMSVDY DGTELGVEADERI RTF ORDAAAOAG I F H HL I TL PTY H TAAL T DNLARRY F GEE

A. C 385 NWTINFROOAYDRWAAEGKDVSAYDRA--KLMSAEY DNTELAADADEKI RTFOADAAREAGVFHHLITLPTYHTAALSTHELAKGYFGEE

H.m. 391 NWTLNLRKQVRAQWISEGKI AEADY PDGTALMSAQY DTSELGREADDRLRQF QVDISARAGVFHNLITLPTFHLTAKSTDELSHGYFGED

C.P. 471 GMLGYVKGVQRKEIRQGIACVKHQNMSGSDMGDDHKEYFAGENALKAGGA-KNTSNQFS -

C.m. 471 GMLGYVEGVQRKEIRQGI ACVKHQNMS GS DMGDDHKEYFAGENALKAGGA - NNTSNQFS -

MS GS D I GD DHKE Y FSGEAALKLAGK - DNTMNOF-

R.m. 470 GMLGYVAGVQRKEIRQGIACVKHQNMSGSDIGDDHKEYFSGEAALKAAGK -DNTMNQF--

A.V. $\quad 474$ GMLAY VKGVQRQE I RQSI ACVKHQNMAGSD I GDNHKEYFAGEAALKAGGK - DNTMNQFH -

P.a. 474 GMLAY VKGVQRQELRQGI ACVKHQNMAGSDI GDNHKEYFAGEAALKASGK-DNTMNQFH -

B.j. 535 GMLGYVKNVQRAEIRQGIACVKHQNMAGSDIGDDHKEYFAGEAALKAGGA-HNTMNQFG-

R.p. 487 GMLGY VKNVQRQE I RQG I ACVKHQNMAGSD I GDDHKEYFAGDAALKAGGE - HNTMNQFS -

N.a. 473 GMLGYVKQVQREEIRQGIACVKHQNMAGSDIGDDHKEYFAGEAALKAGGA - HNTMNQFAA

A.C. 473 GMLAY VAGVQRKE I RGG I ACVKHQAMAGSD I GDDHKEIFAGEQALKAGDASKNTMNQFAH

H.m. 481 RMLAYVATVQREEIRRSISAVRHQHEVGSDLGDTFKEMVSGDRALKAGGA-HNTMNQFAA 


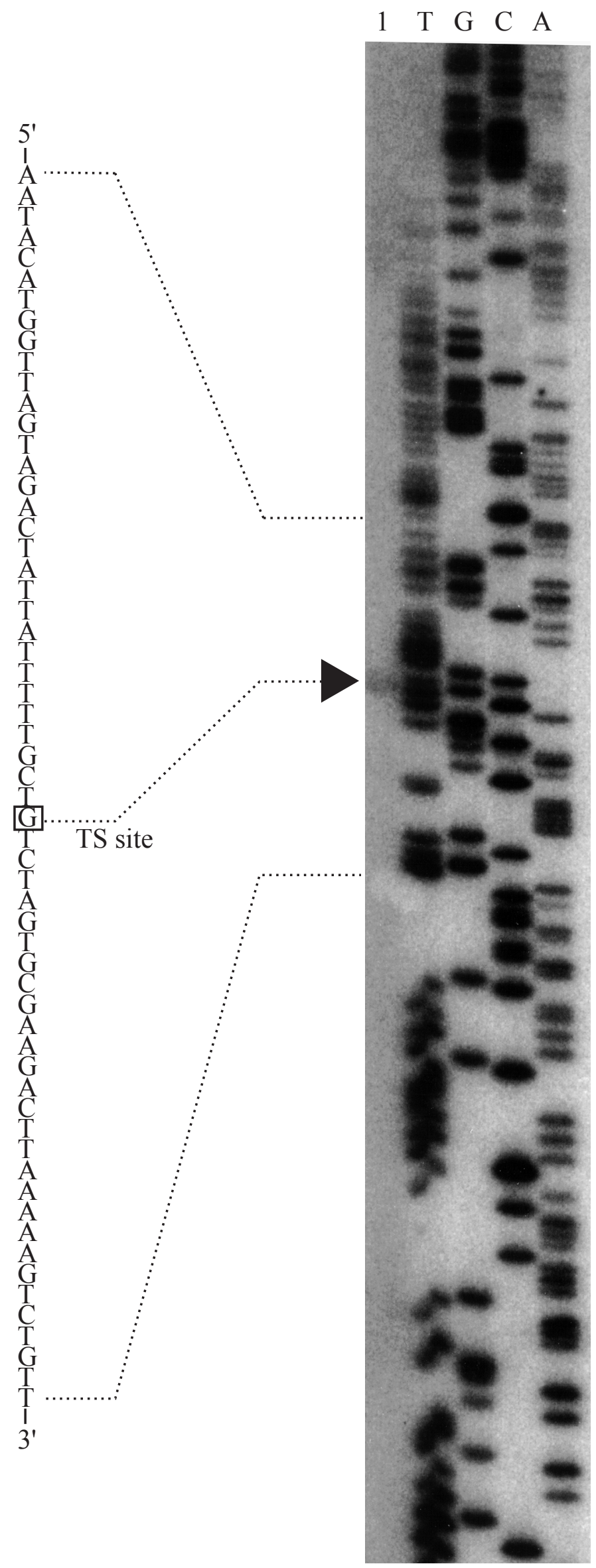

Fig. 4 Sato et al 


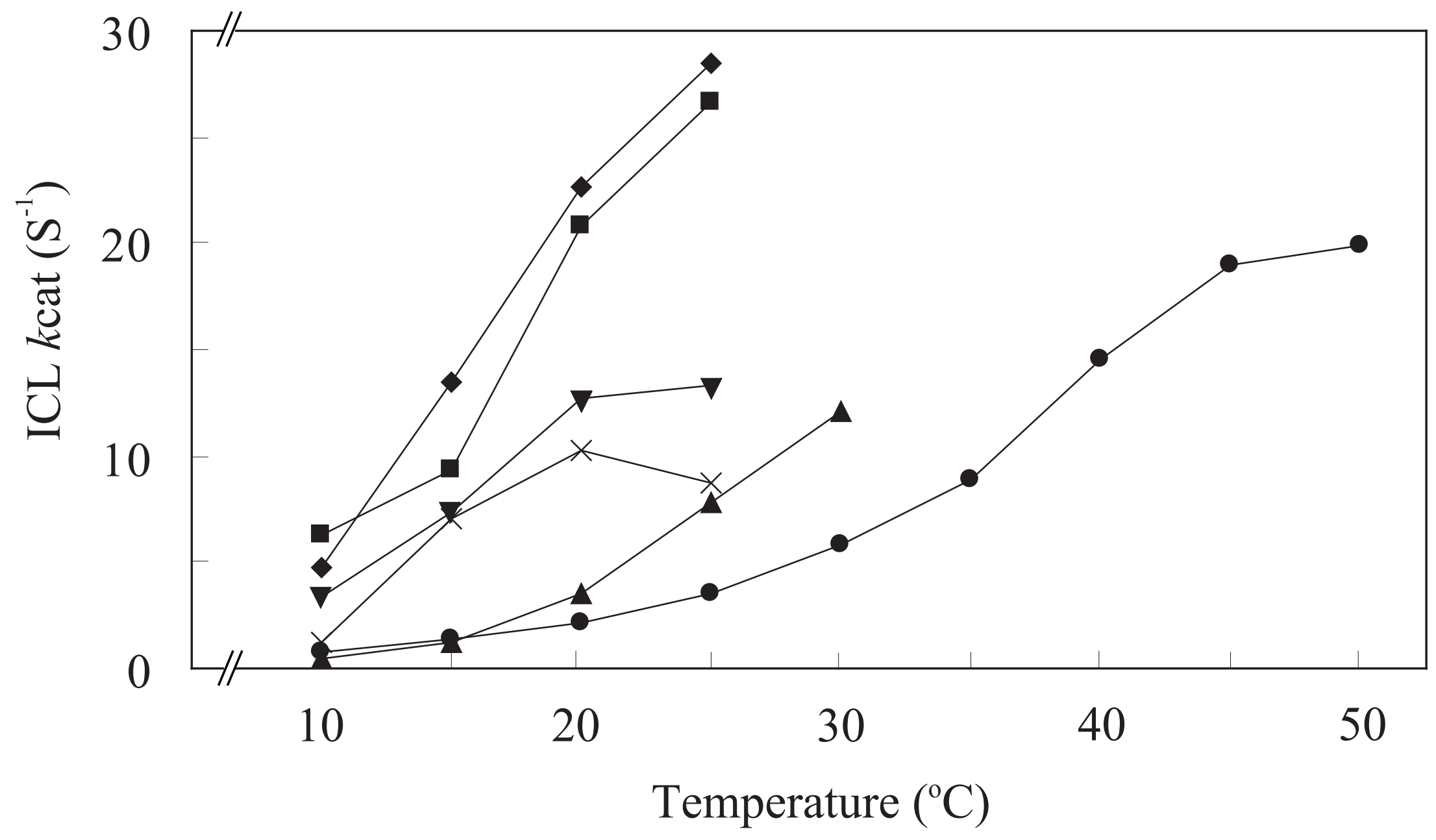

Fig. 5 Sato et al 


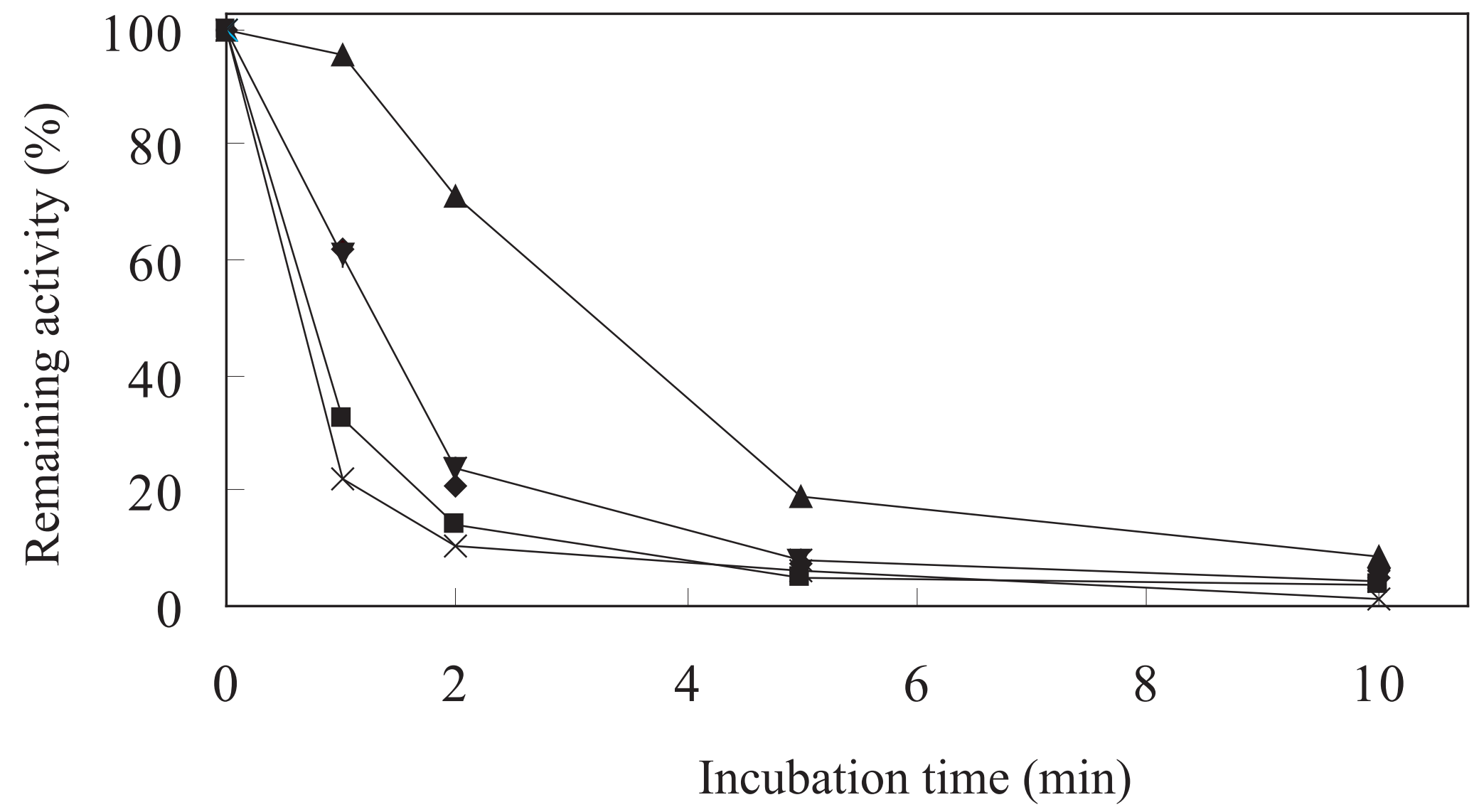

Fig. 6 Sato et al 

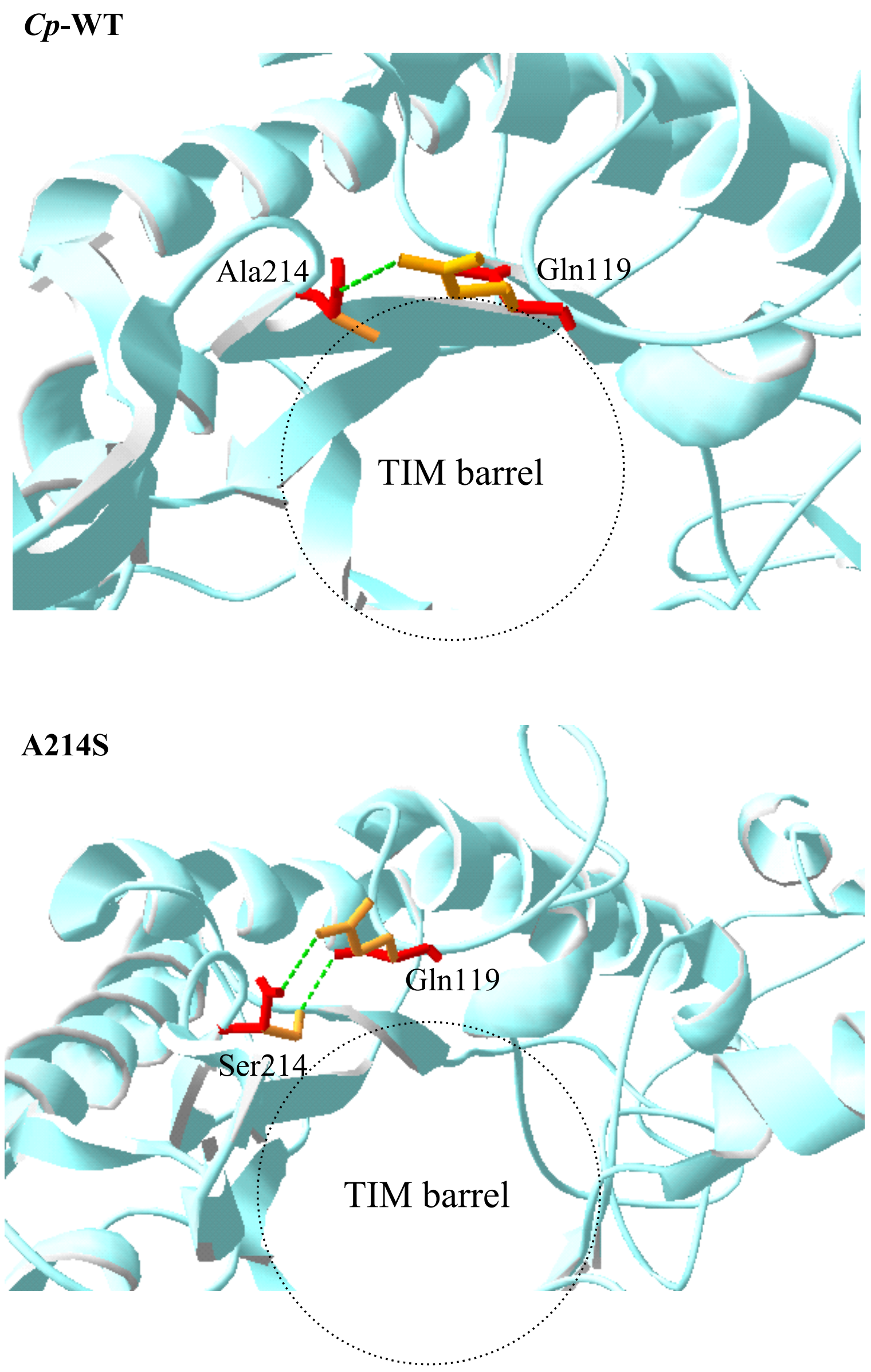

Fig. 7 Sato et al 